\title{
Solvent-Free Selective Hydrogenation of 2-Butyne-1,4-diol over Structured Palladium Catalyst ${ }^{\dagger}$
}

\author{
Lioubov Kiwi-Minsker, Eric Joannet, and Albert Renken* \\ Ecole Polytechnique Fédérale de Lausanne, EPFL-ISIC-LGRC, CH-1015 Lausanne, Switzerland
}

\begin{abstract}
Hydrogenation of 2-butyne-1,4-diol catalyzed by Pd nanoparticles on activated carbon fibers (ACFs) was studied. The ACF support in the form of woven fabrics provides the basis for structured catalytic fixed beds. In the present study, this catalyst was integrated in the stirrer of an autoclave. Hydrogenations were carried out in pure, solvent-free butynediol at temperatures from 352 to $392 \mathrm{~K}$ and hydrogen pressures of 1-2 MPa. The results were compared to those obtained for aqueous solutions at different $\mathrm{pH}$ 's and temperatures of 293-333 K. High selectivities of $\geq 98 \%$ toward 2-butene-1,4-diol at conversions of $\leq 90 \%$ were attained in both systems. Turnover frequencies had comparable values at the same temperature. The activation energy of $30 \mathrm{~kJ} / \mathrm{mol}$ was determined from initial reaction rates. Because this value is identical for the aqueous solution and the solvent-free system, mass-transfer limitations can be excluded for both systems. Concentration-time profiles were quantitatively predicted assuming the Langmuir-Hinshelwood kinetics with weak hydrogen adsorption. Estimated kinetic parameters allow a coherent interpretation of the experimental observations. Catalyst reactivation and multiple reuses were demonstrated.
\end{abstract}

\section{Introduction}

Catalytic hydrogenation has become one of the key processes for manufacturing pharmaceuticals and fine chemicals. ${ }^{1}$ The performances of the hydrogenation process and the product distribution are strongly influenced by the catalyst activity and selectivity, the interaction of chemical kinetics and mass transfer, and the reactor design. Process intensification and integrated environmental protection are important factors for the economy of the process, and this can be achieved by working under solvent-free conditions. The diversity of catalytic hydrogenations and their complexity lead to a multitude of multiphase reactor designs summarized by Dudukovic et al. in a recent review. ${ }^{2}$

In three-phase reaction engineering, one of the main problems to overcome is avoiding internal and external mass-transfer limitations and to attain high selectivity. Therefore, catalyst particles of small diameter are required. In technical application, the minimal size, however, is limited because of catalyst handling like solids charging, filtration, and discharging that often pose safety and environmental problems and can lead to significant catalyst losses. To overcome these problems, we proposed the use of filamentous catalytic materials for multiphase reactions. ${ }^{3}$ Filamentous woven cloths, made of different types of glass, composite mixed oxides of activated carbon, can be used as supports for the deposition of active components: Pt, Pd, oxides of transition metals, etc. ${ }^{4}$ The diameters of the filaments are on the order of several microns and correspond to the diameters of traditional suspension catalysts. Therefore, internal mass-transfer limitations could be avoided. These types of catalysts should be classified as arranged

$\dagger$ Dedicated to Prof. M. P. Dudukovic on the occasion of his 60 th birthday.

* To whom correspondence should be addressed. Tel.: ++41 21693 3181. Fax: ++4121693 3190. E-mail: albert.renken@ epfl.ch. catalysts. 5 They were tested for intrinsic activity/ selectivity in liquid-phase hydrogenation of citral, ${ }^{6}$ benzaldehyde to toluene, ${ }^{3}$ and nitrobenzene to aniline, ${ }^{7-9}$ and for the denitrification ${ }^{10,11}$ of drinking water. The $\mathrm{Pd}$-based catalysts demonstrated high efficiency in these model reactions.

The selective hydrogenation of 2-butyne-1,4-diol (B3) to the corresponding olefinic product was chosen as the model reaction for this study. 2-Butene-1,4-diol (B2) is an important industrial intermediate used for the production of pharmaceuticals, like endosulfan and pyridoxine (vitamin B6), of insecticides, like chlorinated bicyclo[2.2.1]heptene-2-bis(oxyalkylene-5,6) sulfide, and of different bactericides. ${ }^{12}$ It also has wide applications in the paper and textile industries and the manufacture of resins. B2 is produced industrially by partial hydrogenation of $\mathrm{B} 3$. The reaction is usually carried out in an aqueous solution at elevated pressures. ${ }^{13,14}$ In this process, B2 is an intermediate olefinic diol, which can undergo further hydrogenation to give the saturated product butane-1,4-diol (B1) as the main byproduct. Because of the possible double-bond migration and hydrogenolysis of B2, further side products such as butyraldehydes, $n$-butanol, and acetal may be formed. ${ }^{15}$ The attainment of high selectivities for B2 has been the aim of many publications and patents summarized by Telkar et al. ${ }^{15}$ When supported Pd is used as a catalyst, ${ }^{13,14,16}$ mainly cis-B2 is formed, but its selectivity is a function of the temperature, catalyst loading, solvent, addition of base, metal additives, and catalyst support. Besides the $\mathrm{pH}$ of the solution, the rate of hydrogenation, if compared to the rate of mass transfer, influences strongly the selectivity of the intermediate. Therefore, one of the main problems to overcome is the avoidance of transport limitations.

In the present study, woven fabrics of activated carbon fibers (ACFs) were used as supports for the $\mathrm{Pd}$ catalyst. These supports have advantageous characteristics and have been proven to have great potential as 

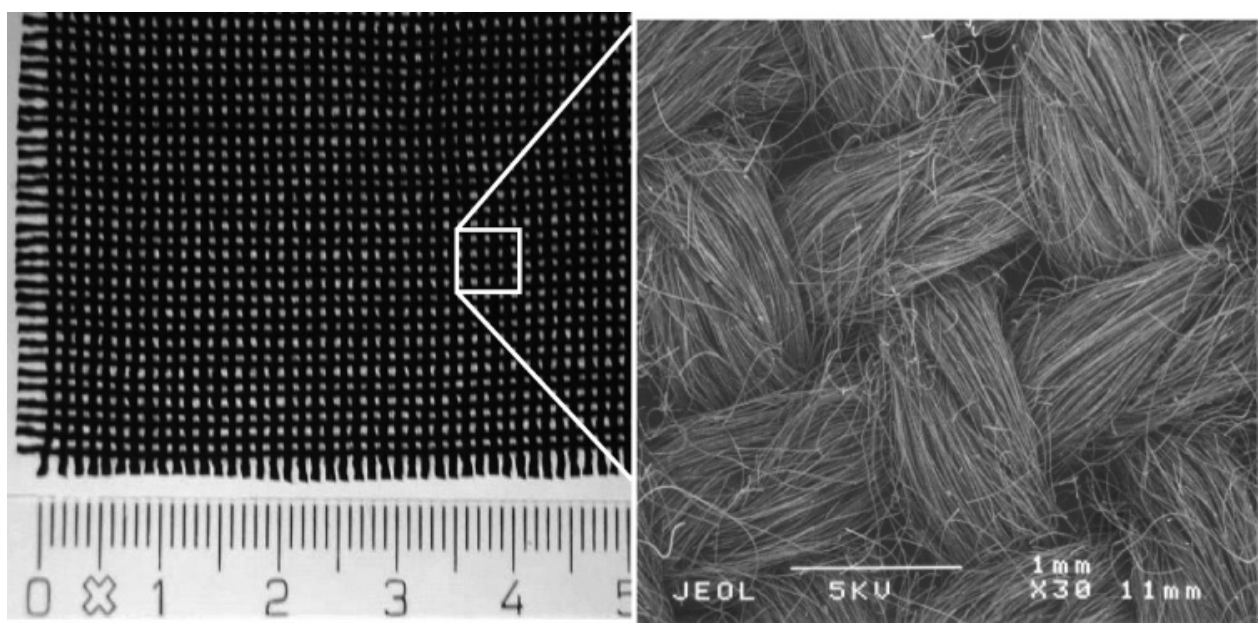

Figure 1. Structure of a woven active carbon fiber support.

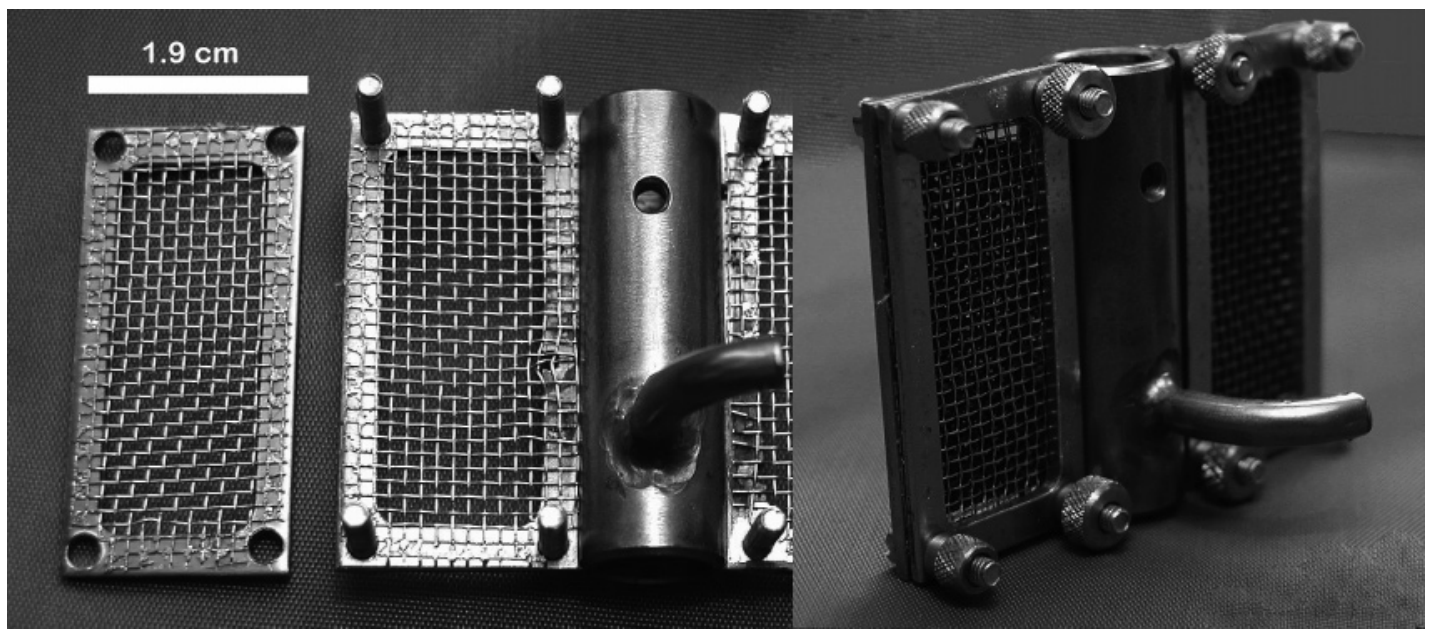

Figure 2. Self-gassing hollow shaft stirrer with a fibrous structured catalyst.

catalytic supports, especially for expensive noble metals, because a high metal dispersion can be achieved via impregnation. The successful use of ACFs for the selective hydrogenation of B3 in aqueous solutions was recently demonstrated. ${ }^{17}$ The present paper reports on the use of Pd nanoparticles supported on ACFs for the selective hydrogenation of pure, solvent-free B3. Besides the activity/selectivity of the catalyst, its stability for multiple reuse is important. The kinetics under solventfree conditions were studied and compared to the hydrogenations in aqueous solutions at different $\mathrm{pH}$ 's.

\section{Experimental Section}

Catalyst Preparation. ACFs made from poly(acrylonitrile) in the form of plain woven fabrics (Taiwan Carbon Technology Co.) were used as supports for catalyst preparation. The fabrics are woven from the long threads of ca. $0.5 \mathrm{~mm}$ in diameter (Figure 1). These threads consist of a bundle of elementary filaments of 3-5 um. The Pd deposition on ACFs was carried out via ion exchange from an aqueous solution of $\mathrm{Na}_{2} \mathrm{PdCl}_{4}$ as described previously. ${ }^{17}$ The loading of Pd was determined by atomic absorption spectroscopy, and the catalysts were characterized via the Brunauer-Emmett-Teller method for the specific surface area and pore size distribution. Pulse chemisorption of carbon monoxide was applied for the determination of $\mathrm{Pd}$ dispersion. ${ }^{17}$
Experimental Setup. The reaction was carried out in a batch reactor $(150 \mathrm{~mL}$ autoclave, Buechiglas Uster, $\mathrm{CH})$, at isothermal conditions kept by a heating jacket. The autoclave is provided with a quantitative gas supply system. The experimental setup is described in detail elsewhere. ${ }^{17}$ The fibrous catalysts were placed between two metal gauzes $(20 \times 40 \mathrm{~mm})$ fixed on the stirrer (Figure 2). The amount of catalyst placed in the reactor was varied between 150 and $35 \mathrm{mg}$. The agitation speed was kept at $1500 \mathrm{rpm}$ to avoid masstransfer limitations. To achieve an efficient gas-liquid contact, a self-gassing hollow shaft stirrer was used. The autoclave was fed with hydrogen (>99.99\%; Carbagas, Zurich, Switzerland) under isobaric reaction conditions.

Pure B3 was charged as a solid ( $\mathrm{mp} 331 \mathrm{~K})$ and molten under argon to prevent degradation of the reactant. After the required temperature was attained, the reactor was flushed with hydrogen and pressurized to the desired level. During the course of the reaction, the pressure of $\mathrm{H}_{2}$ in the reactor was maintained constant by supplying hydrogen from the reservoir at the rate of consumption. The pressure in the $\mathrm{H}_{2}$ reservoir was monitored continuously, allowing in situ measurement of the instantaneous hydrogen consumption.

Product Analysis. Samples of liquids withdrawn from the loop are analyzed by gas chromatography (GC; Auto System XL; PerkinElmer, Wellesley, MA) 


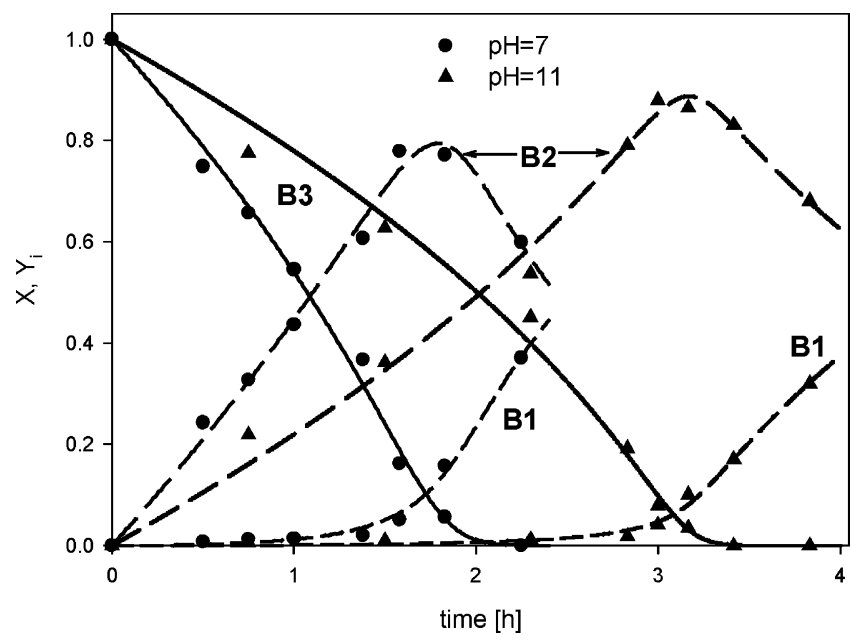

Figure 3. Measured (dots) and predicted (lines) butyne conversion and product yields as a function of time at different $\mathrm{pH}$ 's. Catalyst mass: $2.2 \mathrm{mg}$ of $\mathrm{Pd}$. Temperature: $303 \mathrm{~K}$. Hydrogen pressure: 0.6 $\mathrm{MPa}$. Initial reactant concentration: $1 \mathrm{kmol} / \mathrm{m}^{3}$.

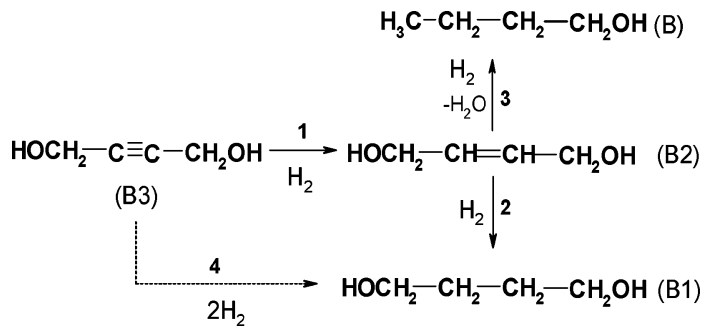

Figure 4. Reaction scheme for hydrogenation of B3.

with $\mathrm{He}$ as the carrier gas and a flame ionization detector. Product separation was performed on a 30-m PerkinElmer Elite series 0.25 -mm capillary column with a $0.25-\mu \mathrm{m}$ coating, at a temperature ramp of $20 \mathrm{~K} / \mathrm{min}$ from 373 to $493 \mathrm{~K}$. Butane-1,3-diol was used as the internal standard for quantitative GC analysis.

The initial reaction rate was used as a characteristic of catalytic activity, $r_{0}\left[\mathrm{kmol} \cdot \mathrm{kg}_{\mathrm{Pd}}{ }^{-1} \cdot \mathrm{s}^{-1}\right.$. The selectivity toward B2 was calculated as $S_{i}=c_{i} \sum c_{i}$, with $i=$ reaction products.

\section{Results and Discussion}

Hydrogenations were performed with pure B3 at different temperatures and hydrogen pressures and for comparison in an aqueous solution. For both systems, the kinetics were studied and the apparent activation energies estimated.

Hydrogenation in Aqueous Solutions. All experiments were carried out at a hydrogen pressure of 0.6 $\mathrm{MPa}$ and at a stirrer rate of $1500 \mathrm{rpm} .{ }^{18}$ Under these conditions, gas-liquid mass-transfer limitations can be efficiently avoided. ${ }^{17}$ To ensure the absence of internal and external liquid-solid mass-transfer influences, catalysts with different $\mathrm{Pd}$ loadings of between 1 and 5 mass \% were used. Because the turnover frequencies (TOFs) were found to be independent of the Pd loading, an influence of the mass transfer on the kinetics can be excluded.

In Figure 3, the conversion of B3 together with the product yields is plotted versus the reaction time for two different $\mathrm{pH}$ values. The temperature was kept at 303 $\mathrm{K}$, and the $\mathrm{pH}$ was adjusted with $\mathrm{KOH}$. As can be seen, the addition of $\mathrm{KOH}$ decreases the reaction rate but increases considerably the yield of the intermediate product B2. These results are in line with those of Telkar et al., ${ }^{15}$ who reported the same behavior for ammonia addition to the reaction mixture.

The experimental results can be rationalized on the basis of the following reaction scheme (Figure 4) and a Langmuir-Hinshelwood model assuming competitive adsorption of the reactants and bimolecular surface reactions. ${ }^{19-21}$ When adsorption of water on the active sites is neglected, the transformation rate of butynediol can be expressed as follows:

$$
\begin{aligned}
& r_{1}= \\
& \frac{k_{1}^{\prime} K_{\mathrm{B} 3} C_{\mathrm{B} 3} K_{\mathrm{H}_{2}} C_{\mathrm{H}_{2}}}{\left[1+K_{\mathrm{H}_{2}} C_{\mathrm{H}_{2}}+K_{\mathrm{B} 3} C_{\mathrm{B} 3}+K_{\mathrm{B} 2} C_{\mathrm{B} 2}+K_{\mathrm{B} 1} C_{\mathrm{B} 1}+K_{\mathrm{B}} C_{\mathrm{B}}\right]^{2}}
\end{aligned}
$$

The hydrogen concentration under reaction conditions is on the order of $5 \times 10^{-3} \mathrm{kmol} / \mathrm{m}^{3}{ }^{22}$ Therefore, the adsorption term for hydrogen can be neglected in the denominator. Because the adsorption equilibrium constants of the olefinic and aliphatic products are small compared to the adsorption constant of the acetylenic reactant, a unique value is proposed, thus reducing the number of adjustable model parameters. The resulting simplified kinetic model is presented in eq 2 with $k_{1}=$

$$
r_{1}=\frac{k_{1} C_{\mathrm{B} 3}}{\left[1+K_{\mathrm{B} 3} C_{\mathrm{B} 3}+K\left(C_{\mathrm{B} 2}+C_{\mathrm{B} 1}+C_{\mathrm{B}}\right)\right]^{2}}
$$

$k_{1}^{\prime} K_{\mathrm{B} 3} K_{\mathrm{H}_{2}} C_{\mathrm{H}_{2}}$ and $K \cong K_{\mathrm{B} 2} \cong K_{\mathrm{B} 1} \cong K_{\mathrm{B}}$.

For the consecutive reactions leading to butanediol and $n$-butanol, analogical expressions can be developed:

$$
\begin{aligned}
& r_{2}=\frac{k_{2} C_{\mathrm{B} 2}}{\left[1+K_{\mathrm{B} 3} C_{\mathrm{B} 3}+K\left(C_{\mathrm{B} 2}+C_{\mathrm{B} 1}+C_{\mathrm{B}}\right)\right]^{2}} \\
& r_{3}=\frac{k_{3} C_{\mathrm{B} 2}}{\left[1+K_{\mathrm{B} 3} C_{\mathrm{B} 3}+K\left(C_{\mathrm{B} 2}+C_{\mathrm{B} 1}+C_{\mathrm{B}}\right)\right]^{2}} \\
& r_{4}=\frac{k_{4} C_{\mathrm{B} 3}}{\left[1+K_{\mathrm{B} 3} C_{\mathrm{B} 3}+K\left(C_{\mathrm{B} 2}+C_{\mathrm{B} 1}+C_{\mathrm{B}}\right)\right]^{2}}
\end{aligned}
$$

The mass balances for butynediol and the reaction products are given by the following differential equations:

$$
\begin{gathered}
\frac{\mathrm{d} C_{\mathrm{B} 3}}{\mathrm{~d} t}=-\frac{m_{\text {cat. }}}{V_{\mathrm{L}}}\left(r_{1}+r_{4}\right) \\
\frac{\mathrm{d} C_{\mathrm{B} 2}}{\mathrm{~d} t}=\frac{m_{\text {cat. }}}{V_{\mathrm{L}}}\left(r_{1}-r_{2}-r_{3}\right) \\
\frac{\mathrm{d} C_{\mathrm{B} 1}}{\mathrm{~d} t}=\frac{m_{\text {cat. }}}{V_{\mathrm{L}}}\left(r_{2}+r_{4}\right) \\
\frac{\mathrm{d} C_{\mathrm{B}}}{\mathrm{d} t}=\frac{m_{\text {cat. }}}{V_{\mathrm{L}}} r_{3}
\end{gathered}
$$

Equations 6-9 were solved numerically with a Rosenbrock method using Berkeley Madonna software. ${ }^{23}$ The model parameters were estimated by fitting the simulated curves to the experimental data. 


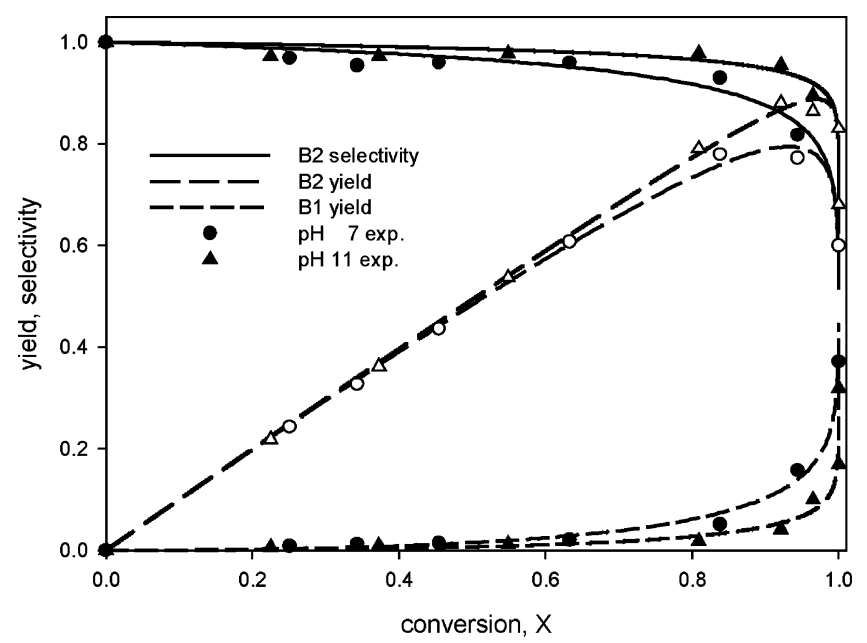

Figure 5. Measured and predicted yield and selectivity toward butenediol as a function of the butynediol conversion (for conditions, see Figure 3).

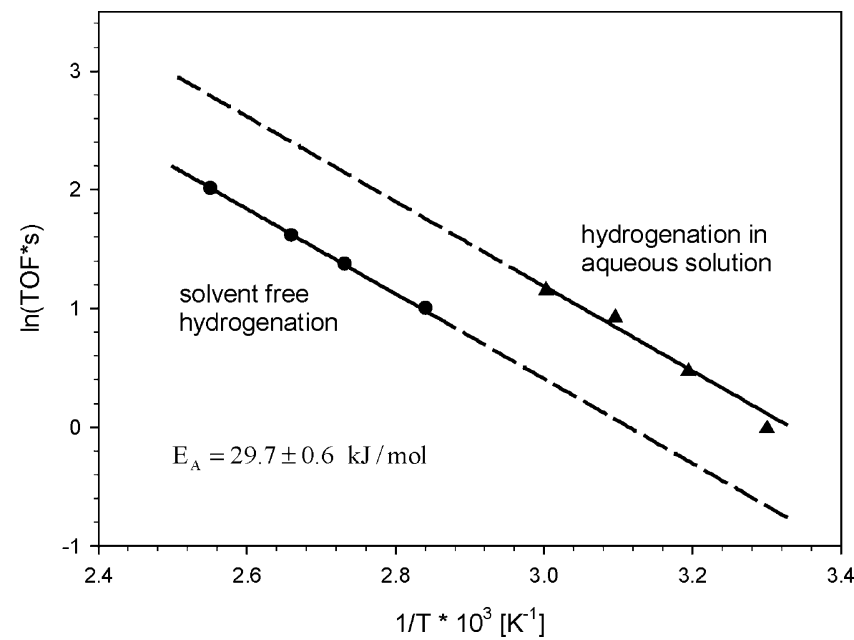

Figure 6. Arrhenius plot for solvent-free and aqueous hydrogenation.

From the simulated concentration and yield profiles, the following main conclusions can be drawn:

(i) The parallel formation of B1, proposed by Winterbottom et al., ${ }^{24}$ can be neglected for hydrogenations in aqueous solutions. ${ }^{17,20}$

(ii) With increasing $\mathrm{pH}$, the rate constant $k_{1}$ drops from $k_{1, \mathrm{pH} 7}=30 \mathrm{kmol} / \mathrm{kg}_{\mathrm{Pd}} \cdot \mathrm{h}$ to $k_{1, \mathrm{pH} 11}=14.6 \mathrm{kmol} / \mathrm{kg}_{\mathrm{Pd}} \cdot$ h.

(iii) The ratio of the global rate constants $\kappa_{i}=k_{i} / k_{1}$ decreases considerably from $\kappa_{2, \mathrm{pH} 7}=0.08$ to $\kappa_{2, \mathrm{pH} 11}=$ 0.034 and from $\kappa_{3, \mathrm{pH} 7}=7 \times 10^{-3}$ to $\kappa_{3, \mathrm{pH} 11}<10^{-6}$.

(iv) The adsorption of the products B2, B1, and B is much weaker at higher $\mathrm{pH}$ 's compared to the adsorption of B3, as shown by the ratio of the adsorption constants: $\left(K / K_{\mathrm{B} 3}\right)_{\mathrm{pH} 7}=12$ and $\left(K / K_{\mathrm{B} 3}\right)_{\mathrm{pH} 11} \cong 450$.

These drastic changes in the kinetic parameters explain the augmentation of the product yield, $Y_{\mathrm{B} 2}$, and selectivity, $S_{\mathrm{B} 2}$, as summarized in Figure 5. In addition, the formation of butanol (reaction 3 ) is nearly completely suppressed at $\mathrm{pH} 11$ because of the small value of $\kappa_{3, \mathrm{pH} 11}$.

With the same catalyst, 2 mass \% Pd on ACF, the initial hydrogenation rates and TOFs were determined in the temperature range from 303 to $333 \mathrm{~K}$. From the Arrhenius plot, an apparent energy of activation of $E_{\mathrm{A}}$ $=29.7 \pm 0.6 \mathrm{~kJ} / \mathrm{mol}$ can be estimated (Figure 6 ). It is important to note that the selectivity for $\mathrm{B} 2$ diminishes with increasing temperature. ${ }^{18}$

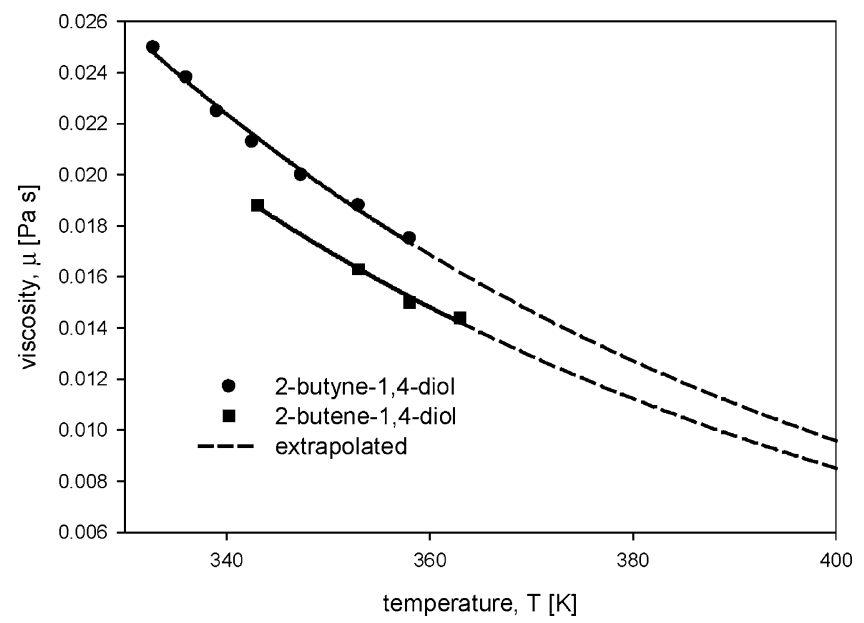

Figure 7. Dynamic viscosity as a function of the temperature of butynediol and butenediol.

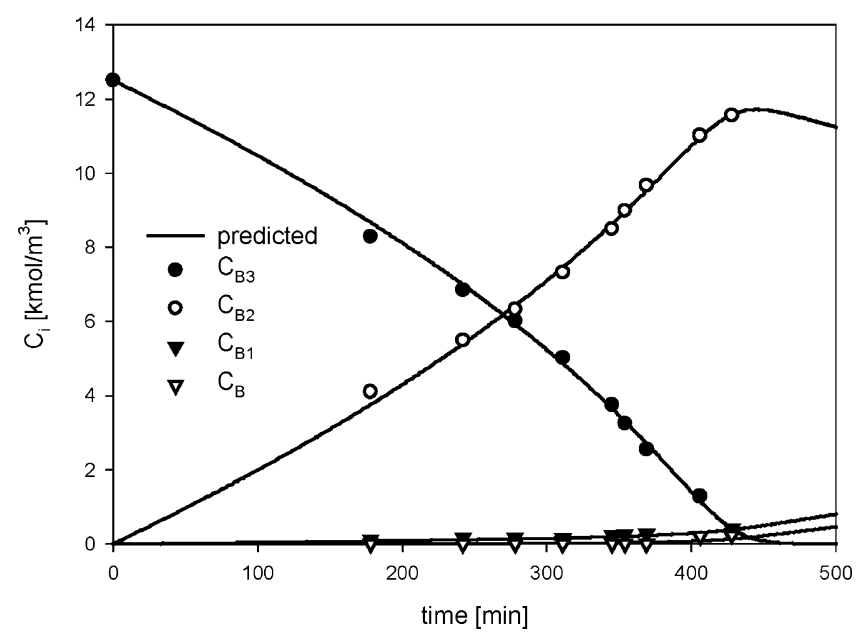

Figure 8. Measured and predicted reactant and product concentrations as a function of time. Solvent-free hydrogenation. Catalyst mass: $4.6 \mathrm{mg}$ of $\mathrm{Pd}$. Temperature: $352 \mathrm{~K}$. Hydrogen pressure: 1.5 MPa.

Solvent-Free Hydrogenation of B3. The hydrogenation of pure B3 leads to a more environmentally friendly process because the separation and recycling of the solvent is avoided. In addition, the process performance is increased.

All reactions under solvent-free conditions were performed with ACF loaded with 4 mass \% Pd. Pd dispersion was found to be $28 \%$, which corresponds to a mean particle diameter of $4 \mathrm{~nm}$. The hydrogen pressure was varied between 1 and $2 \mathrm{MPa}$. B3 has a melting point of $\mathrm{mp}=331 \mathrm{~K}^{12}$ and must be molten under an inert atmosphere. The reaction temperature was fixed between 350 and $500 \mathrm{~K}$ to decrease the viscosity. Within the temperature range, the initial viscosity is roughly 1 order higher than that of the aqueous solution and is between 0.01 and $0.02 \mathrm{~Pa} \cdot \mathrm{s}$ (Figure 7).

At constant temperature, the reaction rate increases linearly with the hydrogen pressure in the mentioned pressure interval, confirming the experimental findings for aqueous systems. ${ }^{17}$ Figure 8 shows typical concentration time profiles for a reaction temperature of 352 $\mathrm{K}$. The experimental results can be described satisfactorily on the basis of the reaction scheme (Figure 4) and the proposed kinetic model (eqs 2-9). The measured and predicted selectivity for the intermediate, B2, is ca. $98 \%$ up to B3 conversions of $90 \%$ and drops to $95 \%$ at $99 \%$ 


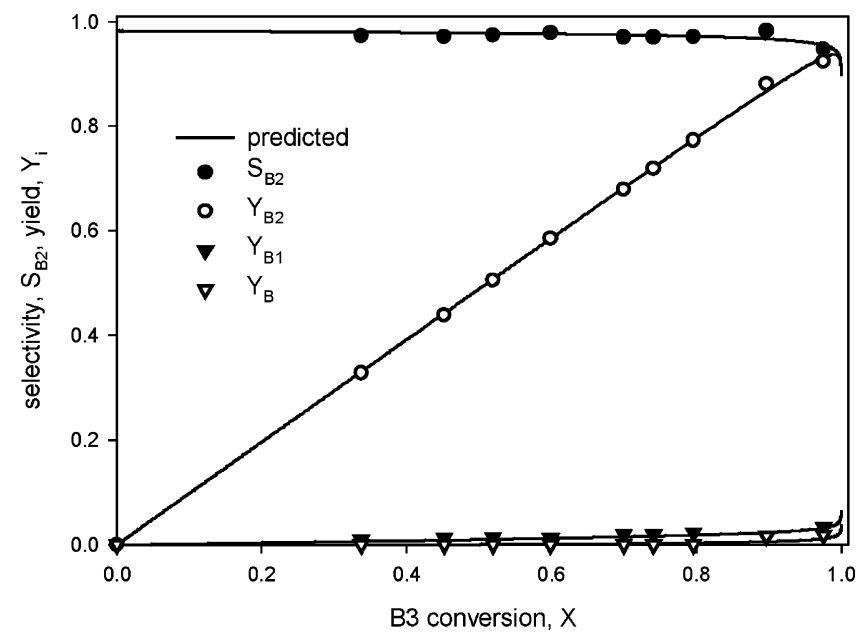

Figure 9. Measured and predicted yield and selectivity toward butenediol as a function of the butynediol conversion (for conditions, see Figure 8).

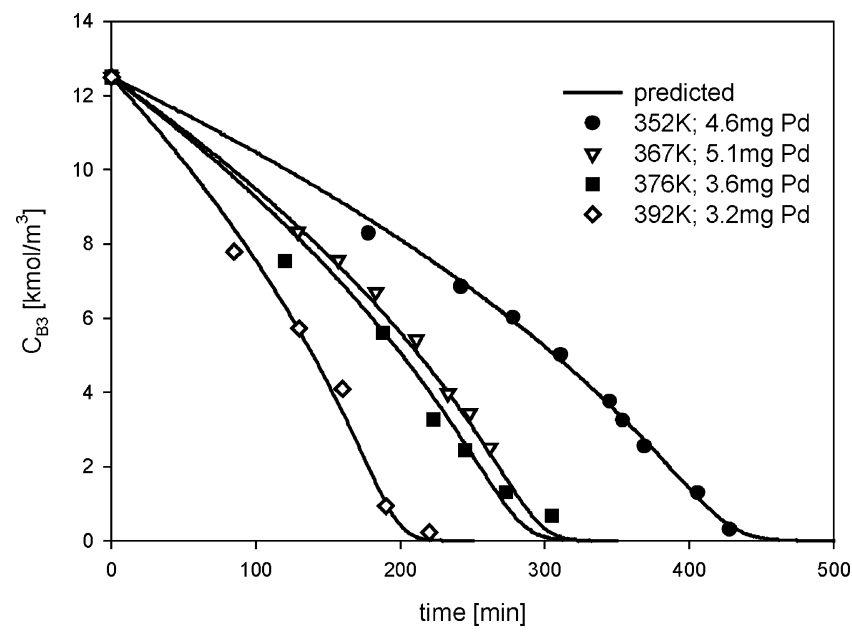

Figure 10. Measured and predicted reactant concentration as a function of time and temperature. Solvent-free hydrogenation. Hydrogen pressure: $1.5 \mathrm{MPa}$.

conversion, as shown in Figure 9. The main difference compared to aqueous systems concerns the direct overhydrogenation of B3 to form B1 described by reaction 4 (Figure 3, eq 5). The ratio of the rate constants $\kappa_{4}=$ $k_{4} / k_{1}$, which was found to be zero in aqueous systems, is estimated to be $\kappa_{4} \cong 0.02$ in the solvent-free mixture. This value for the parallel reactions 1 and 4 is nearly independent of the temperature and explains the initial drop of the B2 selectivity of $S_{\mathrm{B} 2} \cong 0.98$ at $352 \mathrm{~K}$ and $S_{\mathrm{B} 2} \cong 0.97$ at $392 \mathrm{~K}$. In contrast, the consecutive reactions 2 and 3 are much less pronounced: $\kappa_{2} \cong \kappa_{3} \cong$ $10^{-3}$, explaining the high selectivity until near $100 \%$ conversion (Figure 9).

The influence of the temperature on the rate of reaction can be seen in Figure 10, where the reactant concentration is shown as a function of time. On the basis of the initial reaction rate, the dependence of the TOF on temperature can be calculated. The results are shown in Figure 7 in the form of an Arrhenius plot together with the results from the aqueous system. The apparent activation energies of $30 \mathrm{~kJ} / \mathrm{mol}$ are identical for both systems and on the same order of magnitude as reported values. ${ }^{15}$ In contrast, the TOF at the same temperature is about 2 -fold higher in the aqueous system without $\mathrm{KOH}$ addition ( $\mathrm{pH}$ 5.5), as can be seen from Figure 5. However, as pointed out earlier, the

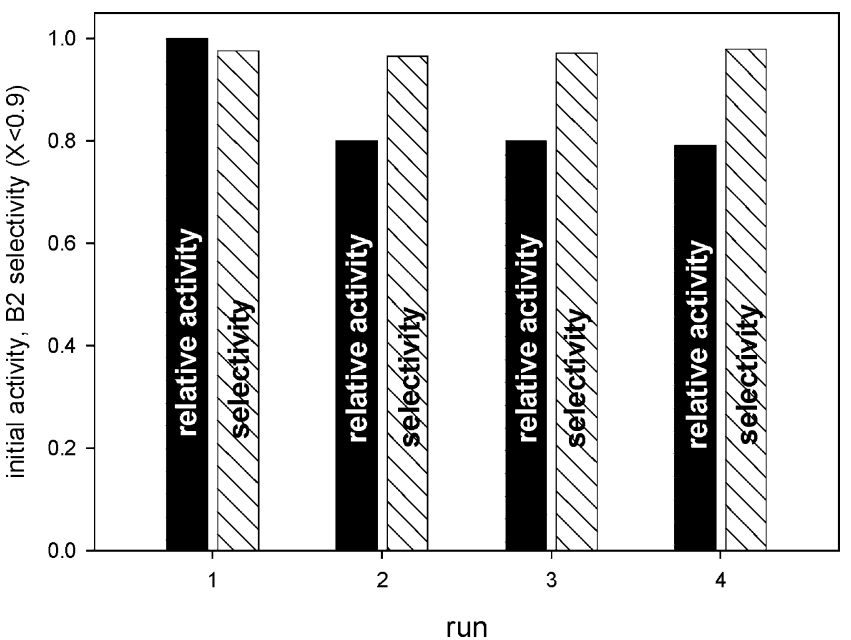

Figure 11. Catalyst reuse for consecutive runs. Solvent-free hydrogenation. Reaction temperature: $352 \mathrm{~K}$. Hydrogen pressure: $1.5 \mathrm{MPa}$

selectivity is rather low. To get selectivities comparable to those of the solvent-free system, the $\mathrm{pH}$ has to be increased, lowering at the same time the TOF. For a reference temperature of $303 \mathrm{~K}$, the following values are estimated: $\mathrm{TOF}_{\mathrm{pH} 5.5}=1.1 \mathrm{~s}^{-1} ; \mathrm{TOF}_{\mathrm{pH} 11}=0.24 \mathrm{~s}^{-1}$, $\mathrm{TOF}_{\text {solv.free }}=0.52 \mathrm{~s}^{-1}$.

For the reuse of the catalyst in aqueous systems, it was simply washed with deionized water after each run and kept in hydrogen-saturated water to prevent deactivation. ${ }^{17,20}$ This procedure was not efficient for the solvent-free system. In this case, oxidation-reduction of the catalyst was necessary to get stable activities. This was obtained with an oxidative treatment in air at $393 \mathrm{~K}$ for $24 \mathrm{~h}$ followed by a reduction of $2 \mathrm{~h}$ at 393 $\mathrm{K}$ under $2 \mathrm{MPa}$ of hydrogen pressure. The results are presented in Figure 11. After an initial drop of $20 \%$ after the first run, the activity remains constant and the selectivity did not change.

\section{Conclusion}

1. Hydrogenation of B3 was selectively catalyzed to butenediol by Pd nanoparticles supported on ACFs. The use of ACF supports in the form of woven fabrics allowed catalyst integration in the stirrer of an autoclave.

2. Hydrogenations were carried out in aqueous solutions at different $\mathrm{pH}$ 's and with pure, solvent-free butynediol at elevated temperatures. Butenediol selectivities of $\geq 98 \%$ for conversions up to $90 \%$ were obtained in both systems. TOFs had comparable values at the same temperature. Potassium was found to be important for improving the selectivity toward butenediol in aqueous solutions.

3. The proposed kinetic model allowed the prediction of concentration-time profiles for all reaction components and the estimation of the kinetic parameters. The activation energy was found to be $\sim 30 \mathrm{~kJ} / \mathrm{mol}$ for both systems.

4. The catalyst reuse without loss in activity/selectivity was demonstrated.

\section{Acknowledgment}

The authors gratefully acknowledge the financial support from the Swiss National Science Foundation and the German Max-Buchner-Forschungsstiftung. 


\section{Literature Cited}

(1) Machado, R. M.; Heier, K. R.; Broekhuis, R. R. Developments in hydrogenation technology for fine-chemical and pharmaceutical applications. Drug Discovery Dev. 2001, 4, 745-755.

(2) Dudukovic, M. P.; Larachi, F.; Mills, P. L. Multiphase catalytic reactors: A perspective on current knowledge and future trends. Catal. Rev. -Sci. Eng. 2002, 44, 123-246.

(3) Kiwi-Minsker, L.; Yuranov, I.; Höller, V.; Renken, A. Supported glass fibers catalysts for novel multi-phase reactor design. Chem. Eng. Sci. 1999, 54, 4785-4790.

(4) Kiwi-Minsker, L. Novel structured materials for structured catalytic reactors. Chimia 2002, 56, 159-163

(5) Structured catalysts and reactors; Cybulski, A., Moulijn, J. A., Eds.; Chem. Ind. (Dekker): New York, 1998; Vol. 71.

(6) Salmi, T.; Maki-Arvela, P. M.; Toukoniitty, E.; Neyestanaki, A. K.; Tiainen, L. P.; Lindfors, L. E.; Sjoholm, R.; Laine, E. Liquidphase hydrogenation of citral over an immobile silica fibre catalyst. Appl. Catal. A 2000, 196, 93-102.

(7) Perez, M. M. C.; Martinez de Lecea, S. C.; Solano, L. A. Platinium supported on activated carbon cloths as catalyst for nitrobenzene hydrogenation. Appl. Catal. A 1997, 151, 461-475.

(8) Höller, V.; Wegricht, D.; Yuranov, I.; Kiwi-Minsker, L.; Renken, A. Three-phase nitrobenzene hydrogenation over supported glass fiber catalysts: reaction kinetics study. Chem. Eng. Technol. 2000, 23, 251-255.

(9) Höller, V.; Wegricht, L.; Kiwi-Minsker, L.; Renken, A. Fibrous structured catalytic beds for three-phase reaction engineering hydrodynamics study in staged bubble columns. Catal. Today 2000, 60, 51-56

(10) Höller, V.; Radevik, K.; Yuranov, I.; Kiwi-Minsker, L.; Renken, A. Reduction of nitrite-ions in water over Pd supported on structured fibrous materials. Appl. Catal. B 2001, 32, 143150

(11) Matatov-Meytal, Y.; Barelko, V.; Yuranov, I.; Kiwi-Minsker, L.; Renken, A.; Sheintuch, M. Cloth catalysts in water denitrification. II. Removal of nitrates using $\mathrm{Pd}-\mathrm{Cu}$ supported on glass fibers. Appl. Catal. B 2001, 31, 233-240.

(12) Gräfje, H.; Körnig, W.; Weitz, H.-M.; Reiss, W.; Steffan, G.; Diehl, H.; Bosche, H.; Schneider, K.; Kieczka, H. Butanediols, Butenediol, and Butynediol. In Ullmann's Encyclopedia of Indus trial Chemistry, electronic release; Wiley-VCH Verlag $\mathrm{GmbH}$ : Weinheim, Germany, 2002.

(13) Gouge, M. Preparation des $\gamma$ glycols ethyléniques primaires secondaires et primaires tertiaires. Ann. Chim. 1951, 12, 648678
(14) Hoffmann, H.; Boettger, G.; Bör, K.; Wache, H.; Kräfje, H.; Körning, W. (BASF AG, D-6700 Ludwigshafen). DE Patent 1139 832, 1974.

(15) Telkar, M. M.; Rode, C. V.; Rane, V. H.; Jaganathan, R.; Chaudhari, R. V. Selective hydrogenation of 2-butyne-1,4-diol to 2-butene-1,4-diol: roles of ammonia, catalyst pretreatment and kinetic studies. Appl. Catal. A 2001, 216, 13-22.

(16) Hort, E. V.; Graham, D. E. (General Aniline and Film Corp., New York). DE Patent 1139 832, 1962.

(17) Joannet, E.; Horny, C.; Kiwi-Minsker, L.; Renken, A. Palladium supported on filamentous active carbon as effective catalyst for liquid-phase hydrogenation of 2-butyne-1,4-diol to 2-butene-1,4-diol. Chem. Eng. Sci. 2002, 57, 3453-3460.

(18) Benassuli, Y. Hydrogénation sélective du but-2-yne-1,4diol sur catalyseur structuré au palladium. Diploma Thesis, Ecole polytechnique fédérale de Lausanne, Lausanne, Switzerland, 2001.

(19) Chaudhari, R. V.; Jaganathan, R.; Kolhe, D. S.; Emig, G.; Hofmann, H. Kinetic modelling of hydrogenation of butynediol using $0.2 \% \mathrm{Pd} / \mathrm{C}$ catalyst in a slurry reactor. Appl. Catal. 1987, $29,141-159$.

(20) Kiwi-Minsker, L.; Joannet, E.; Renken, A. Loop reactor staged with structured fibrous catalytic layers for liquid-phase hydrogenations. Chem. Eng. Sci. 2004, in press.

(21) Winterbottom, J. M.; Marwan, H.; Stitt, E. H.; Natividad, $R$. The palladium catalysed hydrogenation of 2-butyne-1,4-diol in a monolith bubble column reactor. Catal. Today 2003, 79, 391399.

(22) Chaudhari, R. V.; Gholap, R. V.; Emig, G.; Hofmann, H. Gas-liquid mass transfer in "dead-end" autoclave reactors. Can. J. Chem. Eng. 1987, 65, 744-751.

(23) Macey, R. I.; Oster, G. F. Berkeley Madonna, 1997-2001.

(24) Winterbottom, J. M.; Marwyn, H.; Viladevall, J.; Sharma, S.; Raymahasay, S. Selective catalytic hydrogenation of 2-butyne1,4-diol to cis-2-butene-1,4-diol in mass transfer efficient slurry reactor. In Heterogeneous catalysis and fine chemicals IV; 1997; Vol. 108.

Received for review September 14, 2004 Revised manuscript received January 10, 2005 Accepted January 20, 2005 